\section{Elena de Lorenzo}

Profesora titular de Literatura Española de la Universidad de Oviedo e investigadora del Instituto Feijoo de Estudios del Siglo XVIII. Especializada en el estudio de la literatura del siglo XVIII, ha publicado artículos sobre censuras, narrativa utópica, teatro y ensayo de la Ilustración y es autora de la monografía Nuevos mundos poéticos. La poesía filosófica de la Ilustración (2000) y editora de los Escritos sobre literatura de Jovellanos (2009). Secretaria de redacción de los $\mathrm{Cu}$ dernos de Estudios del siglo XVIII y miembro de la Junta Directiva de la Sociedad Española de Estudios del Siglo XVIII, coordina la lista SIGLO-XVIII de la Red Académica y de Investigación Española.
La América censurada del siglo XVIII. En torno a las apologías y proyectos de Ramón Diosdado Caballero

\title{
LA AMÉRICA CENSURADA DEL SIGLO XVIII. EN TORNO A LAS APOLOGÍAS Y PROYECTOS DE RAMÓN DIOSDADO CABALLERO
}

\author{
ELENA DE LORENZO ÁLVAREZ \\ Instituto Feijoo de Estudios del Siglo XVIII \\ Universidad de Oviedo \\ xeldelor@uniovi.es
}

\section{RESUMEN}

El objetivo es explorar una vía de investigación para la constitución de un corpus de manuscritos inéditos del siglo XVIII de tema americano, a partir de los expedientes de impresión depositados en la Academia de la Historia, que permiten conocer tanto el contenido de los textos prohibidos y quién, cuándo y por qué se escriben, como quién y por qué decide denegar el permiso de impresión. El eje de este trabajo de muestra son un par de manuscritos de tema americano del jesuita expulso Ramón Diosdado Caballero, que permanecieron inéditos tras denegar la licencia de impresión el Consejo de Castilla, pese a ser apologías de la labor de España en América.

Palabras clave: América, Siglo XVIII, Ilustración, censura, licencia de impresión, manuscritos, apología, Ramón Diosdado Caballero, Jovellanos.

\section{ABSTRACT}

The aim is to explore a line of research to form a corpus of unpublished manuscripts of the eighteenth century about America, from the printing files deposited in the Academy of History, which allow both to know the contents of forbidden texts and who, when and why they were written, and who and why denies the print permission. The focus of this sample work are two manuscripts about America written by Ramón Diosdado Caballero, which remained unpublished because the Council of Castile denied the printing license, despite being apologies for the work of Spain in America.

Keywords: America, eighteenth century, Enlightenment, censorship, print license, manuscripts, apology, Ramón Diosdado Caballero, Jovellanos.

La progresiva catalogación de los fondos de los archivos españoles favorece hoy el acceso a un rico corpus americanista que permaneció manuscrito y viene a ser complementario de esa suerte de literatura oficial constituida preferentemente por los materiales impresos. Conocer esas obras que perma- necieron inéditas e indagar las razones por las que esto sucedió, saber quién, cuándo y por qué se escribieron y quién y por qué niega el permiso de impresión, puede ser fértil vía de investigación tanto para reconstruir una biblioteca que no pudo ser, la imagen de una dieciochesca América censurada o «arregla- 
da» en los procesos de impresión en la metrópoli, como para incorporar a nuevos autores o aproximarnos a nuevos perfiles de autores ya conocidos.

Para la constitución de ese corpus de inéditos de tema americano censurados en el siglo XVIII son de especial relevancia en España los fondos de la Academia de la Historia y los del Consejo de Castilla, que vienen a ser el alfa y el omega del proceso de impresión en este siglo, pues a partir de 1769 el Consejo había comenzado a confiar a la Academia el ejercicio de la censura previa, dejando en manos de la Inquisición sólo la potestad de prohibir libros publicados. De hecho, la Academia vería reforzado su papel como institución censora con el nombramiento de su director como gobernador del Consejo: desde 1783 hasta 1792, Campomanes presidía el Consejo que encargaba las censuras y dirigía la Academia que las emitía.

De las censuras encargadas por la Academia a sus miembros quedaba copia en la misma, y se encuentran inventariadas en el catálogo de Cesáreo Fernández Duro (1899), con indicación del autor del manuscrito, título, quién realizó la censura y si esta fue negativa o favorable ${ }^{1}$; las censuras recibidas por el Consejo, que finalmente dictaminaba en función del informe, se hallan en el fondo de Consejos del Archivo Histórico Nacional, en cuyos expedientes se custodian además, en ocasiones, los manuscritos originales que habían sido censurados.

La investigación sistemática en ambos fondos permitirá la reconstrucción de esa América censurada, esa biblioteca imposible de que este trabajo pretende ser sólo una muestra, cuyo eje son un par de manuscritos de tema americano del jesuita expulso Ramón Diosdado Caballero (Palma de Mallorca, 1740-Roma, 1829): las Consideraciones americanas, excelencia de la América española sobre las extranjeras decidida con bechos y los Medios para estrechar más la unión entre los españoles americanos y europeos, que permanecieron inéditos tras denegar el Consejo de Castilla la licencia de impresión, basándose en el informe remitido por la Academia de la Historia, que a su vez hace suya la censura emitida por uno de sus más conocidos académicos, Jovellanos.

Con carácter general señalaremos ahora que estas obras de Caballero no son estrictamente desconocidas pues, aunque resta el abordaje sistemático de la obra manuscrita del exjesuita, ya señalaba el especial interés de estos inéditos americanistas catalogados por Domínguez Bordona (1935, núm. 7) J. Escalera en el Diccionario bistórico de la Compañia de Jesús (2001, II, p. 1130), y han trabajado con ellos parcialmente Muñoz Pérez (1954) y Marie-Laure Rieu-Millán (1982); que las censuras de las obras están depositadas en la Academia de la Historia (RAH, leg. 11-1-4/8026, 29 y 30), constan en el catálogo de Fernández Duro (1899, p. 423) y han sido editadas (Jovellanos, 2009, 178-180 y 181-187); que los originales de Caballero se hallan en la Real Biblioteca (Consideraciones: II/1843, 235 fols.; Medios: II/2429, f. 135r-170v), donde también se custodia un breve Discurso sobre la oposición que los escritores extranjeros fingen y exageran entre los españoles y americanos (II/2851, f. 270r296)2 ; y que en el Archivo Histórico Nacional se conserva manuscrita una útil Memoria de las tareas literarias de Ramón Caballero, donde él mismo da cuenta de su obra y de las razones que motivaron su escritura (AHN, DiversosColecciones, $30, \mathrm{n}^{\circ}{ }^{\mathrm{o}}$ ).

Ramón Diosdado Caballero es fundamentalmente conocido por los dieciochistas españoles por su obra impresa, especialmente por su continuación de la biblioteca de jesuitas expulsos, por su historia de la tipografía española y por sus trabajos sobre el pintor José Ribera, el españoleto, y la Academia del Pontano. Y en el ámbito americano, claro está, por el revuelo que montaron sus célebres Observaciones americanas y suplemento critico a la historia del exjesuita don Francisco $\mathrm{Xa}$ vier Clavigero, que Caballero firmara en 1784 con el pseudónimo de Filiberto de Parripalma para evitar la edición en España de la Historia antigua de México de Clavigero por juzgarla obra injuriosa a los españoles, y por la censura de Juan Bautista Muñoz denegando la impresión de ambas publicaciones. Esta diatriba fue reconstruida por José Toribio Medina (1962), Charles E. Ronan $(1970,1973)$ y Elías Trabulse (1976), quien además estableció qué hizo luego Caballero con el manuscrito inédito: recuperar buena parte de la argumentación en L'eroismo di Ferdinando Cortese, donde abunda en los vicios que erradicó la conquista (sacrificios, ebriedad y sodomía) y los beneficios y avances que aparejó (cristianización, ilustración y pacificación). Una sistematización actualizada y contextualizada de este proceso de censura puede verse en Carlos W. de Onís (1984), Víctor Peralta Muñiz (2006) y en Bernat Hernández (2011). La importancia de este corpus de censuras de la Academia ya fue reseñada por Rodríguez Moñino (1956) en la dura reseña que hiciera del Catálogo de Tudela de la Orden (1954), donde no se incluía este fondo. Este corpus viene a ser complementario de de censuras generadas en la América hispana (Rovira, 1999).

2

Tanto la Bibliografía de autores españoles de Aguilar Piñal (tomo II, pp. 14-15) como el Diccionario histórico de la compañía de Jesús (2001, p. 1130), referencian únicamente los Medios y las Consideraciones. 
Las cartas abundan en los argumentos de la diatriba, donde pueden leerse jugosos comentarios privados, como los de $\mathrm{Ca}$ ballero sobre su animadversión contra Bartolomé de las Casas (carta $\mathrm{n}^{\circ}$ 22): "Las observaciones del fraile Casas van escritas con alguna fiereza. Hame parecido usarla porque es infinito el daño que nos hace con sus imposturas. En libros, papeles, conversaciones, etc. se nos quiere cerrar la boca con la autoridad de este hombre. He tirado a descubrir su carácter, valiéndome de la pintura que nos dieron de él sus contemporáneos; $y$ es forzoso decir lo que yo, siguiendo sus testimonios. [...] No he podido moderarle [mi estilo], porque he leído muchas veces los libelos de Casas, capaces de trocar en furor la más sufrida mansedumbre». O sobre Clavigero (carta $\mathrm{n}^{\circ}$ 30), el objeto de su manía: "Concluyo avisando a V.E. cómo va haciendo ya la impresión que se temía la Historia italiana de Clavigero. [...] ¿̇Qué efectos podrán allí [en Nueva España] producir las pinturas tan odiosas de los españoles que contiene su historia, no menos denigrativa que la de Robertson, etc.? Exmo. Sor., serán acaloramientos y manías mías. Pero son manías de quien no tiene especie alguna contra el historiador, al que jamás ha tratado; manías de quien se cree estrechamente obligado después del servicio de Dios a servir sobre todo a su Rey y a su Patria; manías, en fin, de quien pide a Dios diariamente continúe $\checkmark$. Exca. los aciertos en el gobierno de Indias». Parece que sólo la muerte pudo librar al ministro de tan persistente autor, pues la correspondencia se prolonga entre 1784 y 1787 y la muerte de Gálvez se produce el 17 de junio de 1787.

La América censurada del siglo XVIII. En torno a las apologías proyectos de Ramón Diosdado Caballero

ELENA DE LORENZO ÁLVAREZ
El caso es que este encontronazo con la censura no arredró a Caballero, quizá porque aunque no pudo ver editadas las Observaciones recibió del Ministerio de Indias por ella seiscientos duros, según consta en la Memoria de las tareas literarias de Ramón Caballero (AHN, Diversos-Colecciones, 30, n. ${ }^{\circ}$ 8). Este procedimiento en absoluto es excepcional entre los jesuitas expulsos; el propio Caballero intentó también que se le retribuyeran las Consideraciones, pero ya sin éxito: «cuya remisión al señor marqués de Bajamar [Porlier, ministro desde 1787] efectuó el autor sin premio alguno de una obra nueva en el asunto, y de gran fatiga». Testimonios como estos han hecho pensar en una promoción de los estudios sobre Indias patrocinada desde el ministerio o en un amparo a los desterrados bajo la forma de subvención de trabajos, de que nunca se ha hallado orden.

Así que apenas cinco años después, en 1789, volvería a la carga con estos otros dos escritos: las Consideraciones americanas y los Medios para estrechar más la unión entre los españoles americanos y europeos.

Del mismo modo que ya sabemos qué son las Observaciones americanas, por qué las escribió y por qué no se publicaron, intentaremos establecer el contenido de estas otras obras, aunque resulta evidente su voluntad apologética y no se pretende aquí hacer un resumen ni una edición de unos textos por otro lado plagados de argumentaciones tópicas y sazonados con algunas llamativas ocurrencias; pero sobre todo comprender cuándo y por qué se escriben y por qué se decide en España denegar el permiso de impresión, aun siendo apologías de la labor de España en América, encomiásticas defensas, a fin de cuentas, de un Estado que paradójicamente no permite su publicación.

Las Consideraciones americanas, excelencia de la América española sobre las extranjeras decidida con bechos debieron de ser pergeñadas poco después de las Observaciones en que Caballero impugnaba a Clavigero. Tal se desprende de la correspondencia sobre las Observaciones mantenida entre Caballero y José de Gálvez, marqués de la Sonora y ministro de Indias, conservada en la Colección Documentos de Indias del Archivo Histórico Nacional (AHN, 5.1.11. DiversosColecciones, 29, $n^{\text {os }} 21-24,28-30$ ), en que queda claro que Gálvez no sólo está al tanto de los progresos y el contenido de la obra sino que fue además activo valedor de la misma, pues presentó el manuscrito ante el rey y giró puntualmente diversos capítulos a Grimaldi, embajador en Roma pero hasta poco antes poderoso secretario de Estado, de quien Gálvez había sido secretario y a quien debía sus ascensos $^{3}$. Precisamente al enviar a Gálvez el 7 de abril de 1785 la tercera y última parte de las Observaciones afirma Caballero:

A tener a mano las historias modernas eclesiásticas y seculares de las provincias de Indias, que aquí [en Roma] faltan del todo, meditara la cuarta parte, demostrando la superioridad de nuestras colonias a todas las extranjeras en todo género de policía, haciendo ver cómo el ministerio español ha trabajado más que ningún otro en ilustrar las suyas, fundando pueblos y ciudades suntuosas con lo mejor de la arquitectura así civil como militar en templos, palacios, fortalezas, puertos, astilleros, fuentes, paseos, canales, puentes y caminos; erigiendo tribunales, cabildos, catedrales, universidades y recogimientos; conduciendo ganados, plantíos, fábricas, imprentas, etc., más que otra nación; empleando hombres insignes así en el gobierno como en la instrucción de los naturales, cuya [sic] costumbres, ritos, lenguas etc., han manifestado al mundo en escritos sin número. Estas y otras muchas ventajas que de modo alguno, o muy diminutamente, gozan las colonias holandesas, inglesas, etc., pueden recogerse de las nuestras muy semejantes en cuanto lo permite la variedad del terreno a las provincias de la culta Europa. El argumento es sin duda grandioso y del mayor lustre para nuestro gobierno y ministros. Pero se requieren otros libros y papeles que los que ofrece este país (AHN, 5.1.11. Diversos-Colecciones, $\left.29, n^{\circ} 24\right)$.

Tal es el índice fiel de las Consideraciones, concebidas por tanto originalmente en 1785 como una cuarta parte de las subvencionadas Observaciones. El lustroso y grandioso argumento es fiel al contenido apologético de la obra y al método comparativo utilizado en ella, hasta el punto de que José Muñoz Pérez (1954) trabajó con las Consideraciones americanas analizando el cotejo que Caballero establece entre las ciudades de la América española y las anglosajonas para defender la excelencia de la América española.

Tanto las Consideraciones como los $\mathrm{Me}$ dios, de que hablaremos a continuación, son sometidos a censura en 1789: Antonio Porlier envía a la Academia el manuscrito de ambas obras el 4 de octubre de ese año. El proceso fue breve: la Academia encarga la censura a 
Jovellanos, éste la gira el 7 de enero de 1790 y la Academia dice asumirla unánimemente en su totalidad, dando parte al Consejo de Indias el 9 de abril. La motivada censura de Jovellanos razona que las Consideraciones americanas, excelencia de la América española sobre las extranjeras decidida con bechos

viene a ser una de tantas apologías como va produciendo nuestra edad, para hacer ver que cuanto han escrito los extranjeros de nosotros no es otra cosa que un montón de infundadas e injustas invectivas dictadas por la malevolencia y por la envidia. El objeto de la presente es persuadir y aun demostrar con hechos la excelencia de nuestras Indias sobre todas las colonias que poseen los extranjeros en aquel continente, cotejando el estado de la población, agricultura, industria y comercio de unas y otras, y sacando de este paralelo inducciones que ciertamente no son muy concluyentes, a lo menos a mi juicio. Y aunque en este concepto pudiera esta obra calificarse de tan inútil como otras de su especie, con todo, atendiendo a la diligencia con que el autor recogió en gran número de historias y relaciones los hechos en que debía fundarse, y a que, por otra parte, no hay en su obra cosa que se oponga a la religión, a las buenas costumbres ni a las regalías de S.M., creo que se le puede conceder la licencia que solicita (Jovellanos, 2009, pp. 178-180).

En principio, parecía que Caballero vería las Consideraciones impresas, más por cumplir con la máxima imprescindible -no contener nada contra la religión, las buenas costumbres ni las regalías de S.M.- que por ser de utilidad alguna; a fin de cuentas Jovellanos reconoce que el exjesuita ha trabajado con fuentes adecuadas, pero advierte que la argumentación de Caballero es lábil y subraya la inutilidad de estas apologías empeñadas en responder a la leyenda negra codificada principalmente por la historiografía inglesa y francesa -en vanguardia, las historias de De Pauw, Raynal y Robertson, bien escoltadas por obras literarias como la Alzira de Voltaire, las Cartas persas de Montesquieu o Los incas de Marmontel-. Desde el punto de vista ilustrado, no podría haber crítica más contundente, pero ello no podía implicar legalmente la denegación del permiso de impresión.

El problema es que junto a las Consideraciones se incluía un apéndice, los Medios para estrechar más la unión entre los españoles americanos y europeos, que según la Memoria «fue recibido del sor. marqués de Bajamar por la importancia del asunto con aceptación y elogio, exhortando al autor, aunque sin premio alguno, a concluir la obra siguiente [las Consideraciones] que prometía». De su contenido da idea cabal la descripción del censor: «Contiene cierto proyecto para arreglar la justa distribución de los empleos civiles y eclesiásticos de Indias entre los europeos y los criollos, con el piadoso designio de vencer la emulación y los celos que hay entre unos y otros, y contentarlos a todos». Esto ya no era una historia reivindicativa, sino un proyecto, y Jovellanos es claro y contundente:

Prescindiendo, pues, de la utilidad del pensamiento, que no me parece inventado en hora muy feliz, creo que esta especie de proyectos son mejores para llevarlos en derechura al Gobierno que para propuestos al público, por cuya razón, y otras que no dejará de penetrar la Academia, juzgo que sería más acertado negar por ahora al abate Diosdado la licencia que solicita para la impresión (Jovellanos, 2009, pp. 178-180).

El infeliz pensamiento radicaba en que Caballero, sin fuentes ni método y lanzado al ensayo político, negaba el enfrentamiento entre criollos y chapetones, que atribuía, cómo no, a la prensa extranjera, citando también como referentes de este pensamiento la Política Indiana de Juan de Solórzano y Pereira (1648) y las Tardes Americanas de José Joaquín Granados y Gálvez (1778), donde el obispo de Sonora desde el año anterior de 1788 advierte del malestar que las reformas borbónicas están causando en América (Gil Amate, 2012). Al margen de que fuera o no acertado negar en 1789 que los intereses económicos de los criollos eran necesariamente contrarios a los de la metrópoli y que precisamente tras las reformas carloterceristas los chapetones o gachupines habían copado la administración colonial para intentar mantener la sujeción política y económica de estos territorios, hablar públicamente de esto no es conveniente.

Sin embargo, Caballero reconoce luego que tal discordia puede ser cierta y que, de serlo, favorecería los intereses de las potencias extranjeras, y cita como prueba dos referentes, uno casi fundacional y el otro contemporáneo: el enfrentamiento entre Pizarro y Almagro por Cuzco, que el Inca Garcilaso en el propio título de la Historia general del Perú llamara «las guerras civiles, que hubo entre Pizarros y Almagros», y la reciente re-
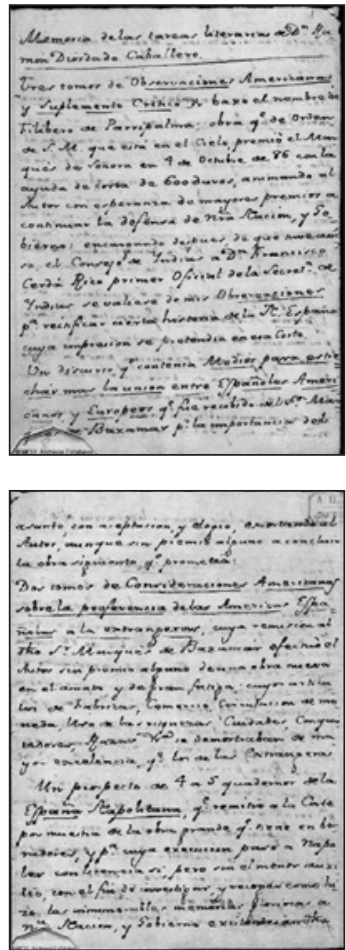

Folio primero (recto y vuelto) de la Memoria de los trabajos literarios de Ramón Diosdado Caballero (AHN, Diversos-Colecciones, 30, n. ${ }^{\circ} 8$ ), donde él mismo da cuenta de su obra y de las razones que motivaron su escritura.

\footnotetext{
La América censurada del siglo xviii. En torno a las apologías y proyectos de Ramón Diosdado Caballero

ELENA DE LORENZO ÁLVAREZ
} 


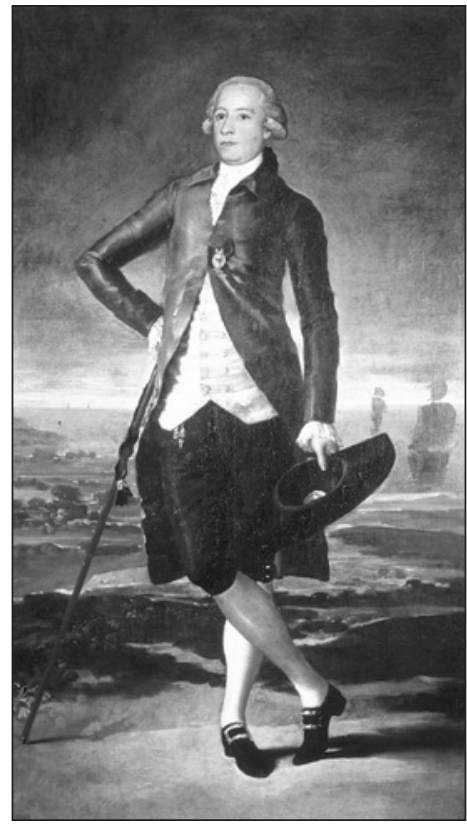

Retrato de G. M. de Jovellanos, con el arenal de San Lorenzo al fondo, por Francisco de Goya, 1780-1783. Museo de Bellas Artes de Asturias.

Este retrato de Jovellanos corresponde a la década madrileña, en que fue activo censor de la Academia; como tal, fue responsable de los informes que finalmente impidieron la publicación de los textos Ramón Diosdado Caballero sobre la América española.

4

Sobre esta representación y su relación con el ideario de las Tardes americanas citado por Caballero véase Gil Amate (2012, pp. 120-124, 160-169). Se lee en ella: «lguales razones, a las que se consideran en la provisión de piezas eclesiásticas, urgen para que los empleos seculares de cualesquiera clase no se confieran sino a los naturales. De ellas hablaremos en contrayendo estos generales principios a favor de los americanos, debiendo por ahora quedar sentado, que la provisión de los naturales con exclusión de los extraños, es una máxima apoyada por las leyes de todos los reinos, adoptada por todas las naciones, dictada por sencillos principios, que forman la razón natural, e impresa en los corazones y votos de los

La América censurada del siglo XVIII. En torno a las apologías y proyectos de Ramón Diosdado Caballero

$\overline{\text { ELENA DE LORENZO ÁLVAREZ }}$

belión de Tupac-Hamaru. El caso es que finalmente apunta que tal competencia podría deberse al problema de la distribución de los altos empleos, que Caballero prefiere confiados a los chapetones, aunque difícilmente podría tal actuación fomentar la unidad entre peninsulares y criollos cuando reiteradamente se recibían memoriales que pedían exactamente lo contrario, como la Representación de la Ciudad de México en favor de sus naturales o sobre que los criollos deben ser preferidos a los europeos en la distribución de empleos y beneficios de estos reinos, dirigida a Carlos III el 2 de marzo de $1771^{4}$.

Para evitar la antes negada y luego supuesta oposición, propone Caballero -de modo mucho más desordenado que en esta apretada síntesis-: en cuanto al clero, que por su influencia pase de la jurisdicción papal a la regia -lo dice un jesuita expulso-, y que se separe a los frailes chapetones de los criollos, enviando a estos al interior -en un oculto destierro-; en cuanto a los criollos, que se les concedan plazas en el Consejo de Indias y se honre a los descendientes de los conquistadores, que se les prohíba publicar papeles fomentando la división y que se les obligue a educarse en España, servir en el ejército español, colocar sus caudales en la metrópoli y ocupar puestos fuera de sus provincias; en cuanto a los indígenas, suprimir el uso de las lenguas indias; en cuanto a los extranjeros en Indias, disminuir el número de licencias;

hombres. Es un derecho que, si no podemos graduarlo de natural primario, es sin duda común de todas las gentes, y por eso de sacratísima observancia. En trastorno de ella se dirige el informe si acaso es cierto a que en esta América todos los beneficios eclesiásticos mayores, y empleos seculares de primer orden, se confieran a los españoles europeos con exclusión de los naturales queriendo acaso cohonestar la trasgresión de los derechos contrarios por la razón de no ser los europeos propiamente extranjeros en la América, que felizmente reconoce el dominio de Vuestra Majestad. [...El español] viene a gobernar unos pueblos que no conoce, a manejar unos derechos que no ha estudiado, a imponerse a unas costumbres que no ha sabido, a tratar con unas gentes que nunca ha visto... Nunca nos quejaremos que los hijos de la antigua España disfruten de la dote de su madre; pero parece correspondiente que quede para nosotros la de la nuestra. Lo alegado persuado, que todos los empleos públicos de la América, sin excepción de alguno, debían conferirse a sólo los españoles americanos, con exclusión de los europeos». El documento en J. E. Hernández y Dávalos (1985) y en S. Bernabeu Albert (2006).

\section{5}

"A fin de que se instruya a los indios en los dogmas de en cuanto a los chapetones, no permitir que se establezcan más en Indias; en cuanto a las guarniciones, moverlas de plaza en plaza y enviar a los Caballeros de Malta para que defiendan las posesiones; en general, fomentar el afecto al rey, haciéndole distribuidor de gracias y empleos -que habrá que multiplicar para que haya más puestos que ofrecer y que agradecer-, y fomentar con premios el espíritu de fraternidad entre criollos y chapetones; $y$, al fin, evitar el aumento de la población de Indias salvo en las fronteras, porque su abundancia sólo sirve para hacer la guerra y porque Inglaterra perdió sus colonias porque las pobló demasiado.

Salvo la concesión de la representación de criollos en el Consejo de Indias, obligar, suprimir, disminuir, separar, mover, probibir son los verbos de acción que predominan en las medidas que se han de adoptar con los indígenas y los criollos -sean jóvenes, militares, o frailes-. Algunas de las medidas propuestas por Caballero ya se habían tomado, otras se tomarían pronto y algunas iban francamente contra la política ilustrada.

Cabe reseñar que cuando Caballero pide la prohibición de las lenguas indígenas, Carlos III ya había publicado la Real Orden de 10 de mayo de 1770, Para que en los Reynos de las Indias, islas adyacentes y de Filipinas, se pongan en práctica y observen los medios que se refieren y ha propuesto el Arzobispo de México, a fin de conseguir que se destierren los diferentes idiomas de que se usa en aquellos dominios y sólo se bable el castellano ${ }^{5}$. nuestra religión en castellano y se les enseñe a leer y a escribir en este idioma, que se debe extender y hacer único y universal en los mismos dominios por ser el propio de los monarcas y conquistadores, para facilitar la administración y pasto espiritual a los naturales y que éstos puedan ser entendidos de los superio res, tomen amor a la nación conquistadora, destierren la idolatría, se civilicen para e trato y comercio; y con mucha diversidad de lenguas no se confundan los hombres, como en la torre de Babe [...] y se llegue a conseguir el que se extingan los diferentes idiomas de que se usa en los mismos dominios, y sólo se hable el castellano, como está mandado por repetidas leyes, reales cédulas y órdenes». El documento completo en Solano (1991). Comentaba Rosenblat (2002, p. 105): «El liberalismo, representado por Carlos III, era absolutista en materia de lengua. Que se extingan los diferentes idiomas y que sólo se hable castellano. Los ideales de la ilustración imponían a los indios, con todo rigor, las luces de la lengua española. Es e triunfo de los juristas contra los teólogos. Frente a la vieja actitud misionera, catequizadora, se abría paso a los imperativos políticos del Estado. $Y$ se enunciaban como una aspiración de unidad: un peso, una medida, una moneda, una lengua». 
Más encaminado iba en su propuesta de prohibición de que los extranjeros pasaran a América, que ya había sido dispuesta por la Casa de Contratación en 1505, lo que no es óbice para que pudieran legalizar su situación mediante las "cartas de naturaleza», que exigían haber residido diez años, estar casado con españolas y ser dueños de propiedades -este proceso no se contemplaba para las mujeres ni para los no católicos-y las «cédulas de composición», en que el pago de una cantidad permitía compensar el «delito de extranjería», según anduviera la situación del fisco. A lo largo del siglo XVIII varias disposiciones van endureciendo la legislación y pronto llegará la más efectiva (Larriátegui, 1817, pp. 3-11; González Beltrán, 1996-1997, pp. 104-108). Mediante la Real Cédula de 20 de abril y la Instrucción de 21 de julio de 1791, Carlos IV abre un proceso de regularización y ordena la confección de censos específicos, las "matrículas de extranjeros». Queda así establecido que para permanecer legalmente en territorio español (peninsular o americano) han de ser católicos, jurar fidelidad a la religión y al soberano, renunciar a cualquier fuero de extranjería y romper cualquier lazo de dependencia con su país de origen, en quien no buscarían amparo en caso de prisión, expulsión ni confiscación de bienes. En el contexto de 1789 y de la cercana guerra con la Francia revolucionaria, Caballero parece palpar lo que está en el aire, pues no se puede interpretar esta matrícula como un mero censo, sino como un elemento de control social para evitar la propaganda de ideas subversivas -el 24 de febrero se habían suprimido todos los periódicos, salvo la Gaceta- que manifiesta una general sospecha de desafección de todo extranjero.

En cuanto a la cuestión demográfica, poco coincidía Caballero con su interlocutor, que juzgaba positivo este crecimiento en tanto favorecía el incremento del poder productivo del trabajo; esto, pese a la conocida advertencia de Thomas Robert Malthus en el Ensayo sobre el principio de población (1798) sobre un posible desequilibrio entre el aumento geométrico de la población y el aritmético de los medios de subsistencia, que Malthus, clérigo al fin, proponía paliar con la continencia. Caballero no llega a tanto.

El caso es que la Secretaría de Gracia y Justicia de Indias recabó un segundo informe, que la Academia encomendó de nuevo a Jovellanos (2009, pp. 181-187). La situación es peculiar, pues no es frecuente que se solicite un segundo informe y menos que de hacerse se encargue al mismo censor. Lógicamente, el asturiano se sintió obligado a legitimar su decisión ante sus pares y la censura defendida el 11 de marzo de 1790 es demorada, argumentada y mucho más dura. De hecho, Capmany recuerda esta censura en 1792, cuando como secretario de la Academia reivindica las tareas científicas de la misma, sobre todo en lo que a Indias atañe, y señala que con frecuencia se ha ayudado «a sus autores para la corrección y rectificación de sus escritos, en cuyos prolijos trabajos cree haber cumplido no pequeña parte de los cargos de su oficio", y concluye: «en algunas de estas obras casi se puede asegurar que la Academia ha trabajado tanto como sus autores» (1796, p. LXXII).

Jovellanos va desgranando en la censura reflexiones de distinto calado: que si la oposición de chapetones y criollos es supuesta, el escrito es inútil; que mejor sería indagar los males antes de proponer remedios; que separar a chapetones y criollos no haría más que generar más división; que llenar de conventos chapetones las costas supondría fomentar la vocación de los emigrantes sin fortuna «como si allá y acá no tuviese bastantes [clérigos]»; que sería injusto obligar a la juventud criolla a educarse, a servir en el ejército y trasladar sus fortunas a España; que lo de enviar malteses a Indias es una ocurrencia; que el aumento de población no es bueno sólo para ejército, sino también para el desarrollo económico; que Inglaterra perdió sus colonias no por tenerlas muy pobladas sino "por haberlos querido oprimir con impuestos, por haberles negado los derechos de ciudadanos y por no dejarlos gozar de la felicidad que se habían labrado ellos mismos»; y que «en caso de elegir uno de los dos caminos de perderlas, el de la humanidad es, cuando no más trillado, más justo que el de la opresión y más digno del espíritu de la religión y aun de la política». \begin{tabular}{l}
$\begin{array}{c}\text { La América censurada del siglo } \\
\text { xviii. En torno a las apologías y } \\
\text { proyectos de Ramón Diosdado } \\
\text { Caballero }\end{array}$ \\
\hline ELENA DE $L O R E N Z O$ ÁLVAREZ
\end{tabular} Campomanes podríguez de Bayeu (copia de A. R. Mengs) 1777. Real Academia de la Historia.

Como presidente del Consejo de Castilla y director de la Academia de la Historia, Campomanes encabezó desde 1783 hasta 1792 las dos instituciones que regían el proceso de censura: el que las encargaba y el que las remitía.

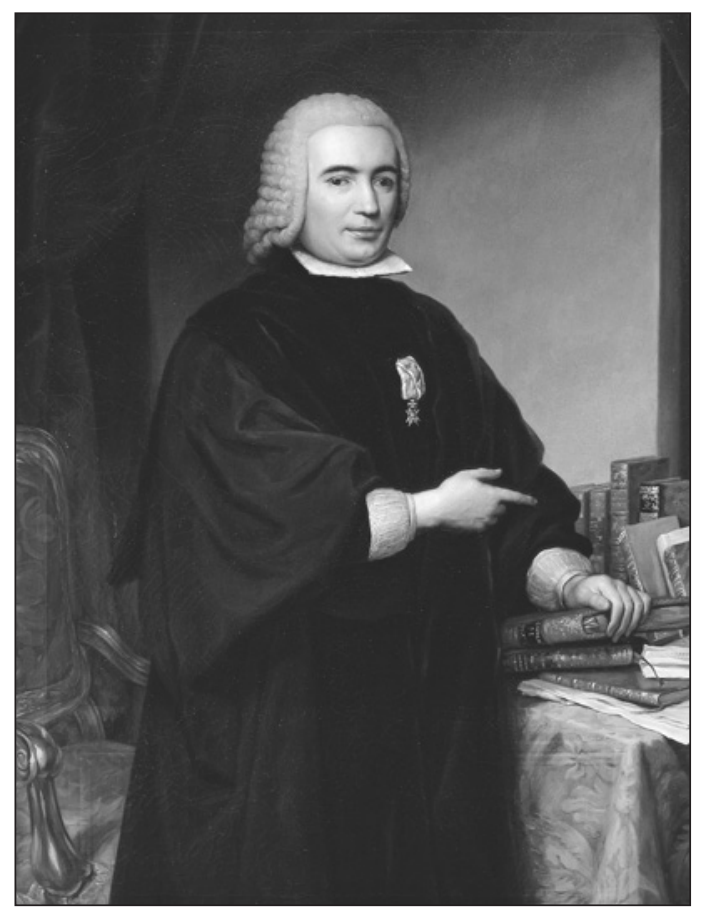


No es momento de recabar las abundantes opiniones de Jovellanos sobre la independencia americana, pero tres meses antes de morir exponía claramente en carta a lord Holland: "Tengo sobre mi corazón la insurrección de América de que usted me habla, y no puedo dejar de detestar y odiar con todo él a los que la fomentan. Dícenme que Blanco es uno de sus más ardientes sopladores; yo no he visto siquiera un número de su periódico; pero si es cierto lo que oigo contar de sus discursos, no hallo dictado bastante negro con que caracterizar su conducta. Fomentar este fuego en un extraño, fuera impru dencia; en un nacional es una cruel indignidad. No basta para disculparla, suponer una cabeza llena de la manía y cavilaciones democráticas, porque deben callar los estímulos de la opinión donde hablan los sentimientos de la probidad. Prescindiendo de los principios de esta defección de nuestros hermanos, basta poner los ojos en sus autores, para calificarla. No son los pobres indios los que la promueven: son los españoles criollos, que no pelean por sacudir un yugo, que desde el principio se trató de hacer ligero, sino por arrebatar un mando que envidian a la metrópoli. ¿Qué pueden pedir que no les hayan dado o estén prontas a dar las Cortes? [...] No, amigo mío, no; no son éstas las cuestiones del día, por más que lo parezcan. Se trata de una escisión, de una absoluta independencia, y sobre esto es la lucha. Yo no sé quién la fomenta; sé que sin ajeno auxilio no pueden vencer en ella los insurgentes» (Jovellanos, 1990, pp. 478-480).

7

Antonio Alcedo (Quito, h.17341812), miembro de la Academia de la Historia desde 1787, es el autor del conocido Diccionario geográfico-histórico de las Indias Occidentales o América (17861789) y de la Biblioteca Americana. Catálogo de los autores que han escrito de la América en diferentes idiomas y noticias de su vida y patria, años en que vivieron y obras que escribieron (1806). Alcedo cita a Agüeros en el primer tomo de su Diccionario (1786, p. 753) entre aquellos curiosos colaboradores que de-

La América censurada del siglo XVIII. En torno a las apologías y proyectos de Ramón Diosdado Caballero

ELENA DE LORENZO ÁLVAREZ

Obviamente, la censura volvió a ser negativa: "Concluyo con decir que esta obra, no recomendada ni por su objeto, ni por su oportunidad, ni por su doctrina, y, antes bien, desfavorecida por sus vacilantes principios, por su política dura e irreflexiva, y, sobre todo, por su inutilidad, no es digna, en mi opinión, de la luz pública». Posiblemente, la sólida argumentación de esta segunda censura de marzo de 1790 motivó la denegación de impresión no sólo de los Medios, sino también de las Consideraciones. Por vía reservada de Gracia y Justicia de Indias, una Real Orden de 20 de abril de 1790 establece que las obras no se publiquen "por las sólidas y prudentes reflexiones en que lo funda [la Academia]».

Y esta es la breve historia de una América imaginada y censurada en un diálogo virtual entre dos peninsulares que nunca la pisaron: la que imaginó Ramón Diosdado Caballero, un denodado apologeta de la obra de España en América -denodado, aunque ineficaz, pues no las vio publicadas-; y la que censuró Jovellanos, cuyo celo ilustrado prefería los argumentos a las apologías.

Para valorar las censuras en su justa medida y matizar las razones del censor cabe reseñar, por último, que Jovellanos revisó otras siete obras sobre la América española, dando paso a seis (Coronas González, 2007) ${ }^{6}$.

Especialmente dura fue la extensa censura del Compendio histórico de los descubrimientos del Nuevo Mundo de Bernardo de Estrada, también académico, firmada a dos manos por Jovellanos y Vargas Ponce el 9 de marzo de 1781 (Jovellanos, 2009, 8-27). Además de reseñar que mucho tiempo les llevó el «impertinente cuidado de corregir la ortografía», van desgranando defectos en la distribución y elección de la materia histórica, ora omiti$\mathrm{da}$, ora copiosa, ora «viciosa y reprobable», bien por ser contraria «ya a la verdad, ya a la imparcialidad histórica», bien por caer en supersticiones como asegurar que la conquista fue «verdaderamente milagrosa» o defender la predicación de santo Tomás en América. Es sabido que en la concepción historiográfica ilustrada los milagros y la historia eclesiástica

seando contribuir al bien público le giraron algunas noticias.

8

El convento franciscano de Santa Rosa de Ocopa, funda- do en 1725 para evangelizar la zona interior de Perú y la Amazonia, se sitúa en una estratégica zona de frontera, donde los misioneros vienen a representar a la corona.

son objeto de especial atención y se insiste en que han de ser sometidos, como todos los hechos reseñados, a verificación documental e interpretación racional (Baras Escolá, 1991). Para los defectos de estilo piden que, simplemente, se eche un vistazo general al texto. Devuelta la obra, la segunda censura también fue negativa, y la airada carta enviada por el autor a la Academia no tiene desperdicio, pero nada consiguió: tampoco la América de Bernardo de Estrada vio la luz.

Más medida fue la censura de la Colección o relación de los progresos hechos por los religiosos de santa Rosa de Ocopa de Pedro González de Agüeros, firmada por Jovellanos y Antonio Alcedo 7 el 14 de noviembre de 1788 y encargada a la Academia por el Consejo de Indias (Jovellanos, 2009, pp. 164-165). Esta obra, que viene a ser una memoria propagandística de la labor franciscana en América, ha de contextualizarse en el marco de expansión y consolidación de esta orden a raíz de la expulsión de los jesuitas ${ }^{8}$. La obra adolece según los censores de graves defectos: «Los hechos que contienen se apoyan sobre la fe de varios documentos que se dicen presentados a $\mathrm{S}$. M. y no han venido a la Academia, y por lo mismo ni necesita, ni puede admitir censura alguna». Y los mapas "no tienen escala, ni consta si las latitudes y longitudes señaladas son efecto de observaciones y medidas astronómicas o puramente voluntarias, como se puede presumir». Pero nada contenía la obra que pareciera contrario a las leyes ni a la religión, así que dieron paso a la publicación, aunque finalmente no parece que fuera llevada a cabo?.

Sin embargo, Jovellanos dio paso a la traducción de Bernardo María de la Calzada de la Alzira de Voltaire el 22 de septiembre de 1784 (1788), señalando que éste estaba prohibido por el Santo Oficio y que su contenido no podía dejar de ofender incluso a los españoles menos amantes de su país, pero que la traducción era buena y apenas había errores de versificación (Jovellanos, 2009, pp. 80-81). Y fue muy positivo en su censura

9 En el manuscrito, titulado Colección general de las expediciones practicadas por los religiosos misioneros del orden de San Francisco del Colegio de Pro- paganda Fide de Santa Rosa de Santa María de Ocopa, se data la obra en 1786. La dio a co nocer Julián Heras (1985) como Expediciones de los misioneros franciscanos de Ocopa. 
de 17 de enero de 1787 de la traducción del Compendio de la Historia geográfica, natural $y$ civil del reino de Chile del abate Molina: «La obra original es, en mi dictamen, muy digna de la luz pública, tanto por la excelencia y novedad de su materia, cuanto por el orden, claridad y buen lenguaje en que está expuesta» (Jovellanos, 2009, 131-132) ${ }^{10}$. Y también en el caso de los Fasti Novi Orbis et ordinationum apostolicarum ad Indias de Domingo $\mathrm{Mu}-$ riel (1776), versión ampliada de la del padre Charlevoix que censura el 12 de julio de 1786. Aunque «debe prevenirse que el autor parece de escuela jesuítica, y aun puede conjeturarse que habrá sido un tiempo de esta ropa», señala que este clásico del derecho indiano está escrito con buena latinidad, gusto y erudición y que, como ya corre impreso, no ve razón para oponerse a la petición del librero Plácido del Barco de comercializarlo en España (Jovellanos, 2009, pp. 113-115).

Pero no siempre se trata de que estas ediciones sobre América fueran aprobadas o denegadas, sino también de que fueran «arregladas». Es paradigmática en este sentido su censura de 24 de septiembre de 1783 del tomo I de la Historia política de los establecimientos ultramarinos de las naciones europeas (17841790) del duque de Almodóvar, adaptación de la Histoire philosophique et politique des établissements et du commerce des Européens dans les deux Indes del abate Raynal (1770), donde queda claro que precisamente se publicó por ser adaptación y no traducción: «Estas censuras [las del parlamento de París y el Santo Oficio] y el conocimiento que yo tenía de la misma obra, me obligaron a examinar la presente traducción con el mayor cuidado, y hallo que ha quedado tan limpia de errores e impiedades, que el escrúpulo con que el autor los ha procurado evitar le hizo sacrificar muchos bellos discursos que acaso pudieran correr sin tropiezo» (Jovellanos, 2009, pp. 67-71).

Y volviendo a los «arreglos», pero a los que se hacían en la propia Academia, en un brete debieron de verse Jovellanos y Alcedo cuando en 1788 les enviaron nada menos que el Nuevo sistema de gobierno económico para la América de José del Campillo y Cossío, secretario de Estado y del Despacho Universal de Hacienda, Guerra, Indias y Marina. Reconocen la excelencia del «almacén de donde se sacaron las más de las providencias dadas con el mismo objeto [gobernar la América española] en el presente reinado», pero reprueban: la acrimonia con que algunas partes de esta obra se increpa la dureza de nuestro gobierno, «asegurando que los indios sufren la más dura tiranía», página 9; «que nuestros mayores enemigos no pudieron inventar en daño nuestro mejores arbitrios que los que nosotros hemos tomado para arruinar aquellas colonias», página 14; «que el estado actual de los americanos es poco menos que el del más cruel cautiverio», página 106; «que hoy respiran bajo una opresión cruel, bajo un mando de los españoles, tan tirano, que se hacen servir de ellos como de los más humildes siervos». Semejantes declamaciones exageradas merecerían la desaprobación de la política, aun cuando no tuviesen la de la verdad. Si son inciertas, no merecen la luz pública y, si no lo son, serán más dignas de las tinieblas. No por eso censuramos el celo del autor. Si lo fue quien se supone, y al parecer se confirma por cierta desenvoltura de estilo que se halla en toda la obra, muy propia del carácter de Campillo, diremos que escribiendo como ministro unos apuntamientos reservados para instruir al gobierno y no al público, y en un ramo de administración que estaba, sin duda, entonces en gran desorden, se dejó llevar de su celo y pudo hacerlo sin inconveniente (Jovellanos, 2009, pp. 142-151).

Una cosa era valorar un informe interno y otra muy distinta publicarlo, que tenía sus inconvenientes. El caso es que el Nuevo sistema se publicó al año siguiente (1789), sí, pero convenientemente cepillado: al rastrear todas estas afirmaciones en la edición de Campillo, ya ninguna se halla en ella. Parece que la visión interna y privada de Campillo era mucho más dura de lo que las prensas soportaban $y$, por tanto, de lo que creíamos. Lo que inevitablemente obliga a reflexionar sobre la solidez de conclusiones a que se llega a partir de lo impreso sin reconstruir el proceso de censura en los archivos. Más, cuando se trata de asunto espinoso, como el americano en las últimas décadas del XVIII, en cuyo tratamiento no cabe indulgencia ni tolerancia, como dice claramente Jovellanos:

La Academia debe considerar que censuramos una historia de América; que este objeto ha ocupado recientemente a dos sabias plumas de Francia e Inglaterra, de cuyas obras carecemos por razones que son bien sabidas; que nuestro Cuerpo es el cronista de aquellos países; que su aprobación le haría responsable de todos los defectos de una obra de esta clase, no sólo hacia el público, que carece de ellas, sino también hacia el gobierno, que las desea, pero que no es nada indulgente ni tolerante con cierta especie de reparos (Jovellanos, 2009, p. 26$)^{11}$.
10

Jovellanos no está censurando el Compendio della storia geografica naturale e civile del regno de Chile del jesuita expulso Juan Ignacio de Molina (1740-1829) que se publicara anónimamente en Bologna en 1776, sino que lee la traducción de Domingo de Arquellada del Saggio sulla storia naturale del Chili de Molina (1782), una edición posterior, revisada y aumentada; el texto se publicará, sin embargo, como el Compendio de la historia geográfica, natural y civil del Reyno de Chile. Primera parte, que abraza la historia geográfica y natural (1788).

11

Obviamente, se refiere a $\mathrm{Gi}$ llaumme Raynal, Histoire philosophique et politique des établissement des Européens dans les deux Indes (Ámsterdam, 1770) y William Robertson, History of America (Londres, 1777), normalmente citadas como referencia del pensamiento europeo del siglo XVIII sobre América junto a Corneille de Pauw, Recherches philosophiques sur les Americains (Berlín, 1768-1769).

\footnotetext{
La América censurada del siglo xviii. En torno a las apologías y proyectos de Ramón Diosdado Caballero

ELENA DE LORENZO ÁLVAREZ
} 


\section{Bibliografía}

Aguilar Piñal, Francisco (1981-2002), Bibliografía de autores españoles del siglo XVIII, Madrid, CSIC, 10 vols., tomo II, pp. 14-15.

Alcedo, Antonio (1786), Diccionario geográfico-bistórico de las Indias Occidentales o América, Madrid, Imprenta de Blas Roman, vol. I, pp. 753.

Alcedo, Antonio (1965), Biblioteca Americana. Catálogo de los Autores que han escrito de la América en diferentes idiomas $y$ noticias de su vida y patria, años en que vivieron y obras que escribieron (1806), ed. Pérez Bustamante, Quito, s.e..

Almodóvar, duque de (1784-1790), Historia politica de los establecimientos ultramarinos de las naciones europeas, Madrid, Antonio de Sancha, 5 vols.

Baras Escolá, Fernando (1991), «Política e historia en la España del siglo XVIII: las concepciones historiográficas de Jovellanos», Boletín de la Real Academia de la Historia, 191:2, pp. 295-388.

Batllori, Miguel (1966), La cultura hispano italiana de los jesuitas expulsos, Madrid, Gredos, pp. 477-481, 492-493, 529 y 582.

Bernabeu Albert, Salvador (2006), El criollo como voluntad y representación, Aranjuez, Ediciones Doce Calles /Fundación MAPFRE.

Caballero, Ramón Diosdado (1784-1789), Observaciones americanas y suplemento crítico a la bistoria del exjesuita don Francisco Xavier Clavigero, expediente de censura, Archivo General de Indias, Patronato Real, 296A, R.1.

Caballero, Ramón Diosdado (1784-1786), Cartas a José de Gálvez, AHN, 5.1.11. Diversos-Colecciones, 29, n $\mathrm{n}^{\text {os }} 21,22,23$, 24, 28, 29, 30.

Caballero, Ramón Diosdado (-1789), Consideraciones americanas, excelencia de la América española sobre las extranjeras decidida con hechos, Real Biblioteca, II/1843, 235 fols.

Caballero, Ramón Diosdado (-1789), Medios para estrechar más la unión entre los españoles americanos y europeos, Real Biblioteca, II/2429, f. 135r-170v.

La América censurada del siglo XVIII. En torno a las apologías y proyectos de Ramón Diosdado Caballero

$\overline{\text { ELENA DE LORENZO ÁLVAREZ }}$
Caballero, Ramón Diosdado (h. 1789), Discurso sobre la oposición que los escritores extranjeros fingen y exageran entre los españoles y americanos, Real Biblioteca, II/2851, ff. 270r-296.

Caballero, Ramón Diosdado (s.f.), Memoria de trabajos históricos y literarios de Ramón Caballero, AHN, Diversos-Colecciones, $30, n^{\circ} 8$.

Caballero, Ramón Diosdado (s.f.), Proyecto para la formación de un nuevo Regimiento con la denominación de Cazadores Reales Americanos, B.P./M., ms. 2856.

Caballero, Ramón Diosdado (1793), De prima tipographiae hispanicae, Roma, Antonium Fulgonium.

Caballero, Ramón Diosdado (1798), Richerche critiche appartenenti all' Academia del Pontano, Roma, Salvador Bombelli.

Caballero, Ramón Diosdado (1806), L'eroismo di Ferdinando Cortese, confermato contro le censura nemiche, Roma, Antonio Fulgoni.

Caballero, Ramón Diosdado (1814-1816), Bibliothecae scriptorum societatis Jesu supplementa, Roma, Franciscum Bourlie, 2 vols.

Caballero, Ramón Diosdado (1828), Observaciones sobre la patria del pintor Josef Ribera, Valencia, Benito Monfort.

Calzada, B. M. (trad. de Voltaire) (1788), El triunfo de la moral cristiana o los americanos, tragedia francesa, Madrid, Imprenta Real.

Campillo y Cossío, J. M. (1789), Nuevo sistema de gobierno económico para la América de Campillo y Cossío, Madrid, Benito Cano.

Capmany, Antonio (1796), «Noticia del origen, progresos y trabajos literarios de la Real Academia de la Historia» en Memorias de la Real Academia de la Historia, tomo I, Madrid, Imprenta de Sancha, p. LXXII.

Coronas González, Santos M. (2007), «Las censuras indianas de Jovellanos», Cuadernos de investigación, 1, pp. 41-54.

Domínguez Bordona, Jesús (1935), Manuscritos de América, Madrid, Bliss.

Escalera, J. (2001), Diccionario bistórico de la Compañia de Jesús. Biográfico-temático, ed. Ch. E. O’Neill, J. M. Domínguez, Roma / Madrid, Institutum Historicum / Universidad Pontifica Comillas, vol. II, p. 1130.

Fernández Duro, Cesáreo (1899), «Catálogo sucinto de censuras de obras manuscritas, pedidas por el Consejo a la Real Academia 
de la Historia antes de acordar las licencias de impresión», Boletín de la Real Academia de la Historia, 35, pp. 369-434.

Gil Amate, Virginia (2012), Sueños de unidad bispánica en el siglo XVIII. Un estudio de 'Tardes americanas' de José Joaquín Granados y Gálvez, prólogo de J. C. Rovira, Alicante, Universidad de Alicante (Cuadernos de América sin nombre, 30).

González Beltrán, J. M. (1996-1997), «Legislación sobre extranjeros a finales del siglo XVIII», Trocadero, 8-9, pp. 104-118.

Granados y Gálvez, José Joaquín (1778), Tardes americanas: gobierno gentil y católico, breve y particular noticia de toda la historia indiana, sucesos, casos de la Gran Nación Tolteca a esta tierra de Anábuac, hasta los presentes tiempos, México, Imprenta Matritense de Felipe de Zúñiga.

Heras, Julián (1985), «Expediciones de los misioneros franciscanos de Ocopa (1709-1786) por el P. Pedro González de Agüeros», Archivo Ibero-Americano, 177-178, pp. 3-112; el texto en pp. 22-86.

Hernández, Bernat (2011), «Una vindicación de la conquista en vísperas de las emancipaciones. Hernán Cortés según el abate Ramón Diosdado Caballero (1806)», en Tierras prometidas. De la colonia a la independencia, Barcelona, Centro para la Edición de los Clásicos Españoles / Universidad Autónoma de Barcelona, pp. 131-152.

Hernández y Dávalos, José Evaristo (1985), Colección de documentos para la bistoria de la guerra de independencia de México, México, INHERM, 6 vols., vol. I, pp. 427-438.

Hervás y Panduro, Lorenzo (2007), Biblioteca jesuitico-española de los escritores que han florecido por siete lustros, ed. de A. Astorgano Abajo, Madrid, Libris, pp. 206-210.

Jovellanos, Gaspar Melchor (1990), «Carta a lord Holland» [Gijón, 17 de agosto de 1811] en Obras completas, tomo V, Correspondencia, ed. J. M. Caso González, IFES.XVIII / Ayto. Gijón, pp. 478-480.

Jovellanos, Gaspar Melchor (2009), «Censura de las Consideraciones americanas, excelencia de la América española sobre las extranjeras decidida con hechos de Ramón Diosdado Caballero", en Obras completas, tomo XII, Escritos sobre literatura, ed. E. de Lorenzo Álvarez, Oviedo, IFES.XVIII
/ Ayto. Gijón / KRK Ediciones, pp. 178180.

Jovellanos, Gaspar Melchor (2009), "Censura de los Medios para estrechar más la unión entre los españoles americanos y europeos de Ramón Diosdado Caballero», en Escritos sobre literatura, pp. 181-187.

Jovellanos, Gaspar Melchor (2009), «Censura de la Colección o relación de los progresos hechos por los religiosos de santa Rosa de Ocopa de Pedro González de Agüeros», en Escritos sobre literatura, pp. 164-165.

Jovellanos, Gaspar Melchor (2009), «Censura de la Historia política de los establecimientos ultramarinos de las naciones europeas del duque de Almodóvar», en Escritos sobre literatura, pp. 67-71.

Jovellanos, Gaspar Melchor (2009), «Censura de la traducción de la Alzira de Voltaire de B. M. de la Calzada», en Escritos sobre literatura, pp. 80-81.

Jovellanos, Gaspar Melchor (2009), «Censura de los Fasti novi orbis et ordinationum apostolicarum de Domingo Muriel», en Escritos sobre literatura, pp. 113-115.

Jovellanos, Gaspar Melchor (2009), «Censura del Compendio de la Historia geográfica, natural y civil del reino de Chile del abate Molina», en Escritos sobre literatura, pp. 131-132.

Jovellanos, Gaspar Melchor (2009), «Censura del Compendio histórico de los descubrimientos del Nuevo Mundo de Bernardo de Estrada», en Escritos sobre literatura, pp. 8-27.

Jovellanos, Gaspar Melchor (2009), "Censura del Nuevo sistema de gobierno económico para la América de Campillo y Cossío» en Escritos sobre literatura, pp. 142-151.

Larriátegui, Félix Colón de (1817), Juzgados militares de España y sus Indias, Madrid, Imprenta Real, "Apéndices al I tomo", pp. 3-11.

Medina, José Toribio (1962), Biblioteca hispano americana (1493-1810), Santiago de Chile, Fondo Histórico y Bibliográfico José Toribio Medina, tomo VI, pp. XXXII-XXXIII.

Molina, Juan Ignacio de (1776), Compendio della storia geografica naturale e civile del regno de Chile, Bologna, s.e.

Molina, Juan Ignacio de (1782), Saggio sulla storia naturale del Chili, Bologna, Stamperia di S. Tommaso d'Aquino.

Molina, Juan Ignacio de (1788), Compendio de la historia geográfica, natural y civil del

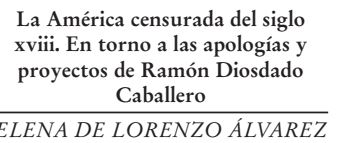


Reyno de Chile. Primera parte, que abraza la historia geográfica y natural, Madrid, Antonio Sancha.

Muñoz Pérez, José (1954), «Una descripción comparativa de las ciudades americanas en el siglo XVIII», Estudios Geográficos, $\mathrm{XV}: 54$, pp. 89-129.

Muriel, Domingo [Cyriacus Morelli] (1776), Fasti novi orbis et ordinationum apostolicarum, Venetiis, Antonium Zatta.

Onís, Carlos W. de (1984), Las polémicas de Juan Bautista Muñoz, Madrid, Ediciones Porrúa.

Peralta Muñiz, Víctor (2006), Patrones, clientes y amigos. El poder burocrático indiano en la España del siglo XVIII, Madrid, CSIC, pp. 240-242.

Rieu-Millán, Marie-Laure (1982), «Projets de formation des élites créoles dans la Péninsule, à la fin du XVIIIe siècle», Mélanges de la Casa de Velázquez, 18:1, pp. 199-214.

Rodríguez Moñino, Antonio (1956), «Los manuscritos americanos en bibliotecas madrileñas. Observaciones bibliográficas a un libro reciente», Bulletin Hispanique, 58:1, pp. 51-76.

Ronan, Charles E. (oct. 1970), "Clavigero: the fate of a manuscript», The Americas, XXVII: 2, pp. 113-136.

Ronan, Charles E. (1993), Francisco Javier Clavigero, S. J. (1731-1787). Figura de la Ilustración mexicana, trad. de C. I. Aguilar, Guadalajara, Universidad [1973].
Rosenblat, Ángel (2002), El español de América, Venezuela, Biblioteca Ayacucho.

Rovira, José Carlos, Varia de persecuciones en el XVIII novohispano, Roma, Bulzoni, 1999.

Solano, Francisco de (1991), V Centenario del descubrimiento de América, Documentos sobre política lingüística en Hispanoamérica 1492-1800, Madrid, Consejo Superior de Investigaciones Científicas, pp. 47 y ss.

Solórzano y Pereira, Juan (1996), Política indiana, ed. de Francisco Tomás y Valiente y Ana María Barrero, Madrid, Fundación José Antonio de Castro [1648].

Sommervogel, Charles (1890-1960), Bibliothèque de la Compagnie de Jésus, Bruxelles- Paris-Louvain, 12 vols., tomo II, pp. 481-483.

Torres Amat, Félix (1836), Memorias para ayudar a formar un diccionario critico de los escritores catalanes y dar alguna idea de la antigua y moderna literatura de Cataluña, Barcelona, Imprenta de J. Verdaguer, pp. 212-214.

Trabulse, Elías (1976), «Un airado mentís a Clavijero", Historia de México, 97, pp. 1-40.

Tudela de la Orden, José (1954), Los manuscritos de América en las Bibliotecas de Espĩa. Catálogo inventario, Madrid, Ediciones Cultura Hispánica.

Fecha de recepción: 14/02/2013

Fecha de aceptación: 29/07/2013
La América censurada del siglo XVIII. En torno a las apologías y proyectos de Ramón Diosdado Caballero

ELENA DE LORENZO ÁLVAREZ 